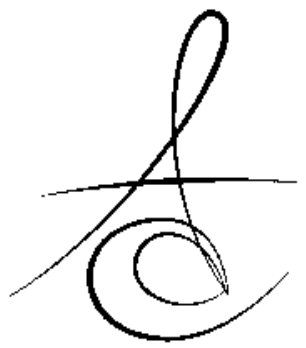

Makale Kodu/Article code: 2231

Makale Gönderilme tarihi: 10.04 .2015

Kabul Tarihi: 15.07.2015

\section{GEÇMİŞTEN GÜNÜMÜZE POSTLAR, YAPIŞTIRICI SİMANLAR VE KOR MATERYALLERİ}

\section{POSTS, LUTING CEMENTS AND CORE MATERIALS FROM PAST TO PRESENT}

\author{
Dr. Gamze KARAÇOLAK*
}

Prof. Dr. L. Şebnem TÜRKÜN*

\section{ÖZET}

Endodontik tedavi görmüş dişlerde kuronal bölgede yoğun bir madde kaybı söz konusu ise restorasyon aşaması karmaşık bir hale gelmektedir. Kuronal bölgedeki aşırı madde kaybı, kanal tedavili dişlerin fonksiyonel kuvvetler karşısında dayanıklıı̆ını azaltmaktadır. 1950'li yıllardan bu yana kuronal bölgedeki doku kayıplarını telafi etmek, yapılan restorasyona destek ve retansiyon sağlamak amacıyla post sistemleri kullanılmaktadır. Günümüzde piyasada çok sayıda post sistemi, yapıştıııı siman ve kor materyali bulunmakla birlikte; teknolojinin ve malzeme biliminin ilerlemesine paralel olarak, bu malzemelerin gelişimi hala sürmektedir. Piyasaya sürülen materyallerin hızla artması ve çeşitlilik kazanmasıyla klinik kullanıma uygunluklarını ve ihtiyaçlara ne kadar cevap verebildiklerini test etmek amacıyla yeni çalışmalara intiyaç duyulmaktadır. $\mathrm{Bu}$ derlemenin amacl, post-kor restorasyonların yapımında kullanılan materyallerin avantaj ve dezavantajlarını değerlendirerek, günümüze dek nasıl değişim ve gelişim gösterdiklerini ortaya koymaktır.

Anahtar Kelimeler: Postlar, Yapıştırıcı simanlar, Kor materyalleri, Monoblok sistemler

\section{GİRİş}

Endodontik tedavili dişlerin biyomekanik dayanıklılık açısından vital dişlerden daha fazla risk taşıdığı bilinmektedir. ${ }^{1,2}$ Bazı araştırmacılar, ${ }^{3}$ bu duruma kaybedilmiş diş dokusu miktarının sebep olduğunu düşünürken, bazıları da dentindeki nem kaybının bu kırılganlığın nedeni olduğunu iddia etmişlerdir. ${ }^{4-6}$ Restore edilecek dişte kalan sağlam doku miktarı, dişin direncini doğrudan etkilemektedir. Bu sebeple endodontik tedavili dişlerin restorasyonunda başarılı olmak

\section{ABSTRACT}

The restoration of endodontically treated teeth may be a challange for the dentist, especially when great damages occured on the coronal part. These large defects will reduce the strength of endodontically treated teeth againts functional forces. From 1950's post systems are being used to compensate tissue loss and support coronal restoration. Nowadays, there are many post systems, luting cements and core materials available on the market. However developments of these materials are still in progress parallel to technology and material science developments. With the increase in the variety of the new materials available on the market; new studies will be needed to test the clinical acceptability and performance of these materials.

The aim of this review is to evaluate the advantages and disadvantages of the materials used for post-core restorations and to present their changes and improvements until today.

Key words: Posts, Luting cements, Core build-ups, Monoblock systems

için dikkat edilmesi gereken temel faktör, diş yapısının mümkün olduğunca korunmasıdır. ${ }^{7,8} \mathrm{Bu}$ yapının korunamadığı, kuron desteğini kaybetmiş, aşırı harap endodontik tedavili dişler, üst restorasyonlarının yapılabilmesi için kökten destek alan post-kor restorasyonlara intiyaç duymaktadır.

Post-kor restorasyonların oluşturulmasında kullanılan postlar yapım tekniklerine göre temelde iki grup altında incelenirler:

*Ege Üniversitesi Diş Hekimliği Fakültesi, Restoratif Diş Tedavisi A.D 


\section{Döküm postlar}

Bu post tipi; kalan diş dokusunun az olduğu, geniş ve düzensiz kanallı dişlerde tercih edilmektedir. Bu yöntemin avantajı, daha az preparasyonla kök kanalına daha uyumlu bir post elde edebilmektir. ${ }^{9}$

\section{Prefabrik Postlar}

Döküm postların yapım aşamalarının uzunluğu ve zorluğu araştırmacıları daha pratik olan prefabrik postlara yöneltmiştir. Bu sistemler kök kanalından koronale doğru uzanarak kor materyaline destek olurlar. ${ }^{10-12}$ Günümüzde piyasada bulabileceğimiz birçok prefabrik post sistemi bulunmaktadır. En yaygın kullanılan prefabrik post sınıflamasını 1987' de Caputo ve Standlee ${ }^{1}$ yapmıştır. Bu sınıflamada prefabrik postlar farkı açılardan değerlendirilir ve alt gruplara ayrilırlar (Tablo 1):

Tablo 1. Prefabrik postların sınıflandırıması

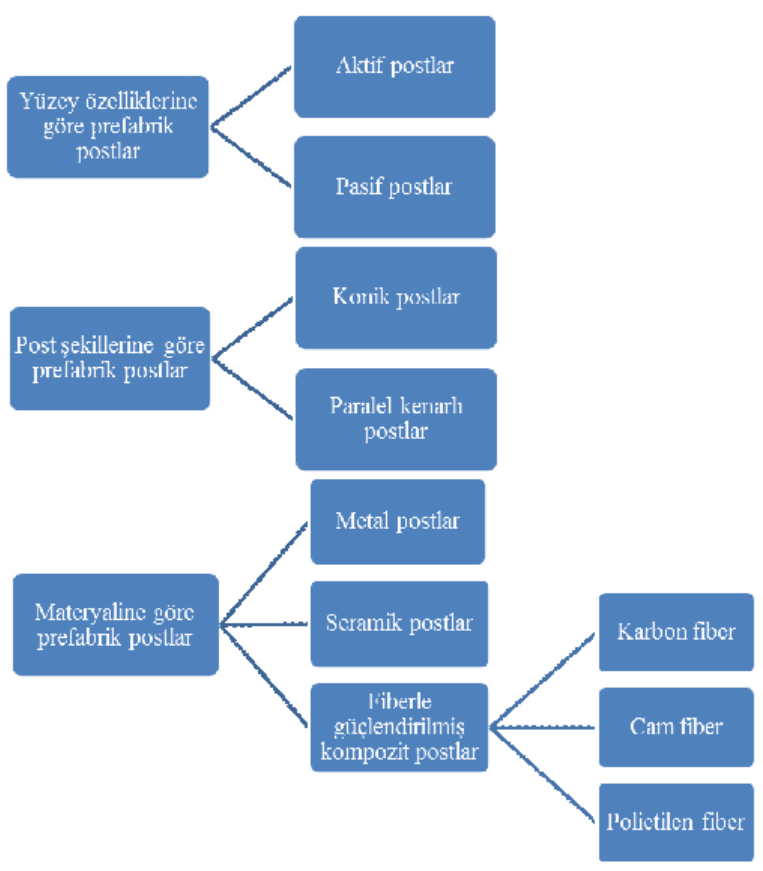

\section{Yüzey özelliklerine göre prefabrik postlar \\ 1.1. Pasif postlar}

Pasif postlar, seçilen post sisteminin frezi ile hazırlanan kök kanalına herhangi bir vidalama işlemi yapılmadan, simantasyon yoluyla retansiyon sağlayan sistemlerdir. Yüzeyleri düz veya yivli olabilir. Paralel kenarlı, konik veya her ikisinin kombinasyonu şeklinde de olabilirler. ${ }^{13}$

\subsection{Aktif postlar}

Yivleri ile kök dentini içine vidalanarak kullanılırlar. Bu gruptaki bazı sistemler direkt olarak dentine vidalanırken, bir kısmı da rehber frezler ile kök kanalında önceden hazırlanan vida yuvasına yerleştirilirler. ${ }^{13}$ Vidalama işlemi saat yönünde yapılır. Paralel veya konik olabilirler. Konik şekilli aktif postlar, neden oldukları kama etkisi ve vidalama işleminden kaynaklanan stres yoğunluğundaki artış nedeniyle kök kırığı oluşturma riski en yüksek olan postlardır. ${ }^{14}$

\section{Post sekline göre prefabrik postlar}

\subsection{Konik postlar} ikiye ayrilırlar. ${ }^{9}$

Konik postlar, düz yüzeyli ve vidalı olmak üzere

\subsection{Paralel kenarlı postlar}

Paralel kenarlı postlar, düz yüzeyli, yivli ve vidalı olmak üzere üçe ayrılırlar. ${ }^{9}$

Günümüzde halen postların retansiyon ve stres dağıııı özelliklerini iyileştirebilmek için farklı şekiller denenmektedir.

\section{Kullanulan materyallere göre prefabrik postlar \\ 3.1.Metal Postlar}

Bu tip prefabrik postlar paslanmaz çelik, nikelkrom veya titanyum alaşımlarından yapilırlar. ${ }^{9}$ Paslanmaz çelik, kırılma ve bükülmeye karşı dayanıklı olmasına rağmen, korozyona direnci düşüktür. Korozyon; retansiyon kaybı, post yapısının zayıflaması hatta kök kııklarına bile sebep olabilir. ${ }^{15,16}$ Ayrıca, metal iyonlarını birikimi, yumuşak ve sert dokularda renk değişikliklerine bazen de diş etinde enflamasyona neden olabilir. Bu durum özellikle yüksek gülüş hattına sahip hastaların anterior dişlerinde estetik problemler oluşturabilir.

Titanyum diğer metallerle kıyaslandığında; biyouyumluluğu ve elastiklik modülünün diş dokularının elastiklik modülüne yakınlığı ve korozyona direnci gibi nedenlerle post yapımı için uygun bir materyal olarak görülmektedir. ${ }^{17}$ Ancak, düşük özgül ağırlığı ve yüksek erime noktası nedeniyle dökümü sırasında birçok problemle karşılaşılabilir. Ayrıca titanyum alaşımların çoğunun radyoopasitesi kanal dolgusunun görüntüsüne yakındır ve radyografide kanal dolgusundan ayırt edilmesi zor olmaktadır. Titanyum postların kırıma direnci soy olmayan alaşımlardan ve paslanmaz çelikten yapılan postlara oranla daha düşüktür ve bu nedenle ince boyutlarda kullanımaları sakıncalıdır. ${ }^{18}$ 
Metal postlar üstün fiziksel özellikleri nedeniyle yaygın olarak kullanılırlar. Ancak bu postların metalik rengi ve ışık geçirme özelliklerinin bulunmayışı estetik sorunlara yol açmaktadır. Bu tip problemlerin çözümünde özellikle tam seramik kuronlarla kombine kullanılabilen metalik olmayan post sistemleri alternatif olabilir. ${ }^{19}$

\subsection{Seramik Postlar}

Seramik sistemlerindeki gelişmelerle beraber, seramikler kanal postu olarak da kullanılmaya başlanmıştır. Postlar için, cam seramikler, alüminyum oksit ile güçlendirilmiş seramikler, freze tekniği ile elde edilen seramikler ve zirkonyum kullanılmaktadır. ${ }^{9}$

\section{Postlar}

3.3.Fiberle Güçlendirilmiş Kompozit

Geleneksel metal post sistemlerinin dezavantajları göz önünde bulundurulduğunda, metal içermeyen ve fiziksel özellikleri dentine benzer malzemelerin kullanımı konusu restoratif diş hekimliğinin hedeflerinden birisi olarak belirlenmiştir. ${ }^{20}$ Duret ve ark. ${ }^{21}$ 1990'da post yapımı için karbon fiberle güçlendirme prensibine dayanan metal olmayan bir materyal geliştirmişlerdir. Laboratuar çalışmalarında, bu materyalle üretilen postların çekme dirençlerinin yüksek olduğu ${ }^{22}$ ve metallerle kıyaslandığında dentine daha yakın elastiklik modülüne sahip olduğu görülmüştür. ${ }^{23}$ Metal postlar herhangi bir deformasyon olmadan lateral kuvvetlere direnç göstererek stresi daha az rijit olan dentine transfer edip, bunun sonucunda kök dentininde çatlak ve kırıklara neden olurken; fiber postların yükleme sırasında esneyip, yükü post ile dentin arasında paylaştırdığı düşünülmektedir. ${ }^{16}$ Günümüzdeki fiber postlar hacimce yüksek oranda devamlı fiber iplik ve fiberlerin içine gömüldüğü birleştirici bir rezin matristen oluşurlar. ${ }^{24}$ Matris polimerleri, genellikle yüksek derecede polimerize ve yüksek çapraz bağlı yapıda epoksi polimerlerdir. ${ }^{25} \mathrm{Bu}$ materyalle paralel, konik, düz yüzeyli veya yivli olmak üzere birçok farklı post elde edilebilir. ${ }^{24}$ Yapılan çalışmalarda dental polimerlerin fiberlerle güçlendirildikten sonra fiziksel ve mekanik özelliklerinin iyileştiği belirtilmiştir. ${ }^{26,27}$ Fiber ile güçlendirilen kompozitlerin fiziksel özellikleri; fiberin tipine, çapına, uzunluğuna, oranına, dağılımına, doğrultusuna ve ıslanabilirliğine göre değişmektedir. ${ }^{28,29}$ Günümüzde post restorasyonlarına direnç kazandırmak amacıyla en sık kullanılan fiber tipleri; karbon fiberler, cam fiberler ve polietilen fiberlerdir. ${ }^{30}$

\subsubsection{Karbon Fiberle Güçlendirilmiş Kompozit Postlar}

Karbon fiberler; inert, biyouyumlu, esneme ve çekme direnci iyi olan materyallerdir. Isıyla genleşme göstermezler, ISI ve elektrik iletkenlikleri azdır, yoğunlukları düşüktür, korozyona dirençlidirler ve rezinle bağlantıları kuvvetlidir. ${ }^{31}$ Karbon fiber ilavesinin dental polimerlerin yorulma dirençlerini, bükme ve çekme dayanımlarını ve elastiklik modüllerini arttırdığı bilinmektedir. ${ }^{32}$ Güçlendirme amaçlı kullanılan fiberler arasında, karbon fiberler en rijit olan malzemedir ${ }^{33}$ ve elastiklik modülleri cam fiberlerden yaklaşık olarak üç kat daha fazladır. ${ }^{29}$ Karbon fiberler koyu renklerinden dolayı estetik problem yaratabildiklerinden, tam seramik restorasyonlarla birlikte kullanımları uygun değildir. $^{32}$ Bazı firmalar karbonun koyu rengini maskelemek için üzeri kuartz fiber kaplı karbon fiber postlar (Örn. Aesthetil Plus, Bisco Inc., Schaumburg, $A B D)$ üretmişlerdir.

\subsubsection{Cam Fiberle Güçlendirilmiş \\ Kompozit Postlar}

Karbon fiberle aşılamayan estetik problemler sonucunda, diş rengine daha yakın renkte, beyaz veya translusent olan cam fiber destekli postlar piyasaya sürülmüştür. Bu postlar aynı zamanda cam türevleri olan, silika fiber veya kuartz fiber olarak da adlandırılırlar. Elastiklik modülleri düşük olan bu postların mekanik özellikleri, karbon fiberlere kıyasla, dentine daha yakındır. Cam fiberle güçlendirilmiş post sistemleri, bir rezin matris içinde elastiklik modülünü etkilemeden postu güçlendirmek için tek yönlü uzanan fiberlerden meydana gelirler. ${ }^{34}$ Cam fiberler, farklı tipte camlardan yapılabilirler. $\mathrm{SiO}_{2}, \mathrm{CaO}, \mathrm{B}_{2} \mathrm{O}_{3}, \mathrm{Al}_{2} \mathrm{O}_{3}$ ve diğer alkali metallerin oksit karışımının amorf bir fazı olan elektriksel cam (E-Cam) en çok kullanılan cam tipidir. Cam fiber postların yapımında optimum estetiği sağlayan kuartz fiberler de kullanılabilir. Kuartz, kristalize form- daki saf silikadır. Bu materyal, düşük termal genleşme katsayısına sahip, doku dostu ve translusent bir materyaldir. ${ }^{35,36}$ Cam fiberlerin uzun dönem başarısı ile ilgili faktörlerden birisi de sızıntıya karşı olan stabiliteleridir.

\subsubsection{Polietilen Fiberle Güçlendirilmiş Kompozit Postlar}

İlk kez Braden ve ark. ${ }^{37}$ tarafından diş dokularına benzer renkleri, yumuşaklıkları ve yüksek yorgunluk direncine sahip olmaları gibi nedenlerle kullanımı önerilen polietilen fiberler; kırılgan olmamaları, 
erimeye karşı dirençleri, hidrofobik ve biyouyumlu olmaları gibi özellikleriyle de son yıllarda sıklıkla tercih edilen fiberler arasına girmişlerdir. Ancak polietilenin polar gruplarının bulunmaması ve yüzey enerjisinin düşük olması nedeniyle, rezin ile bağlantıları zayıftır. Diş hekimliğinde kullanılan polietilen fiber malzemeler genellikle örgü şerit şeklinde üretilirler. ${ }^{38}$

Güçlendirici materyal ile rezin matris arasındaki bağlantı çok önemlidir ve bu ara yüzde stres dağılımının dengeli olması gerekir ki bu da ancak güçlendirici materyal ile rezin arasındaki adezyon ile mümkün olmaktadır. Polimer rezinlerin kimyasal yapıları ara yüzde kuvvetli bağlar oluşturacak aktif gruplar içerir. Eğer güçlendirici materyal yüzeyi, rezine karşı kimyasal eğilim göstermiyorsa, adezyonu arttırıcı maddeler kullanılır. Bunlar ara yüzde rezin ile materyal arasında köprüler oluşturur. ${ }^{39}$ Adezyonu arttırmanın diğer bir yolu ise güçlendirici materyalin kimyasal yapısını değiştirmek ve yüzeyini pürüzlendirmektir. ${ }^{40}$

Postların Simantasyonunda Kullanulan Yapıștırıcı Ajanlar

Postların simantasyonunda doğru simanı seçmek; mikrosızıntıyı önlemek, retansiyonu ve stabiliteyi sağlamak için çok önemlidir. ${ }^{41}$

İdeal bir yapıştırıcı siman materyali;

1. Toksik olmamalı ve çevre dokuları irrite etmemelidir

2. Tükürük ve ağız sıvılarında erimemelidir

3. Yeterli düzeyde dirence sahip olmalıdır

4. Translüsent restorasyonların simantasyonu için optik özellikleri diş yapısına benzer olmalıdır

5. Mine, dentin, metal alaşımlar, porselen ve akrilik rezinlerle iyi bağlantı oluşturmalı ancak kullanılan aletlerden kolayca uzaklaştırılabilmelidir

6. Sıvı haldeki siman materyali düşük viskozitede, ince film kalınlığında ve restorasyonun yerleştirilmesine izin verecek şekilde ağız ısısında uygun çalışma zamanına sahip olmalıdır

7. Yeterli sıkışma, çekme direncine ve adezyona sahip olmalıdır. ${ }^{41,42}$

Postların simantasyonunda geçmişten günümüze sırasıyla; çinko fosfat, polikarboksilat, cam iyonomer ve rezin simanlar kullanılmıştır.

\section{Cinko Fosfat Simanlar}

1800 'lü yıllarda geliştirilmiş en eski, en bilinen ve günümüzde de hala kullanılan yapıştırma simanıdır. Toz kısmının ana bileşeni \% 2-10 magnezyum oksit eklenmiş çinko oksittir. Likit kısmı ise \% 45-60' lik fosforik asit çözeltisidir. ${ }^{43}$ Fiziksel özellikleri karıştırılma sırasında kullanılan toz-likit oranına göre değişmektedir. Maliyeti düşük olan çinko fosfat simanın elastiklik modülü dentine yakındır ve kullanımı da kolaydır. ${ }^{42,44,45}$ Ancak, bu simanlar diş ile kimyasal bağlantı oluşturmazlar, çekme dirençleri düşüktür ve sertleşme süreleri de uzundur. ${ }^{44,45}$

\section{Polikarboksilat Simanlar}

Polikarboksilat siman, dental siman olarak ilk defa Smith tarafından 1968'de kullanılmıştır. Tozu \% 10 magnezyum oksit eklenmiş çinko oksitten oluşmaktadır. Likit kısmı \% 30-45' lik akrilik asit çözeltisidir. Bazı ticari formlarında polimer kurutularak toz kısma eklenmiş ve siman hazırlamak için saf su kullanılmıştır. Polikarboksilat simanın diş dokularına adezyonu iyi, basma direnci yüksek, çözünürlüğü de düşüktür. Çalışma süresi kısa olduğundan hassas bir uygulama gerektirir. ${ }^{44,45}$

\section{Cam Iyonomer Simanlar}

Cam iyonomer siman 1972 yılında Wilson ve Kent tarafından geliştirilen ve en yaygın kullanılan yapıştırma simanıdır. ${ }^{46}$ Tozu kalsiyum floroaliminosilikat camdan oluşmaktadır. Likiti ise poliakrilik asit veya akrilik asit kopolimeridir. Çalışma zamanını ve akıcılığını arttırmak için tartarik asit de eklenmiştir. ${ }^{47}$ Isısal genleşme katsayısı ve ısı iletkenliği diş dokuları ile uyumludur. Mine ve dentinle kimyasal bağlantı oluşturur. ${ }^{44,48}$ Su kaybetmesi ya da kuruması siman hacmini azalttığı için, yüzeyde çatlaklar oluşabilir ve materyalin aşınmaya karşı direnci azalır. Kırılmaya karşı direnci düşüktür. Materyalin maksimum dayanıklılığa ulaşması için bazen birkaç hafta süre gerekebilir, dolayısıyla post simantasyonu için uygun bir siman değildir. ${ }^{44,45,48}$

Geleneksel cam iyonomer simanlara \%20 oranında rezin ilave edilerek oluşturulmuş rezin modifiye cam iyonomer simanlarda gerilme ve aşınma dirençleri arttırılmış, ağız likitlerinde çözünürlük azaltılmıştır. ${ }^{49}$ Ancak bu simanların sertleşme sonrası genleşmeleri nedeniyle post simantasyonunda kullanılmamaları önerilmiştir. ${ }^{50}$

\section{Rezin Simanlar}

Rezin simanlar içerik ve karakteristik özellikler bakımından restoratif kompozitlere benzerler. Diş dokularına kimyasal olarak bağlanabilirken, birçok dental materyale de yapışabilirler. Rezin simanın mineye adezyonu, mikromekanik olarak hidroksiapatit kristallerinde ve asitlenmiş mine yüzeyinde oluşur. Dentindeki adezyon ise, hibrit

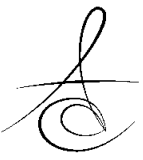


tabakanın altında bulunan demineralize dentin ile mikromekanik olarak sağlanır. ${ }^{51,52}$ Rezin simanlar kompozit rezinlerde olduğu gibi organik matris, inorganik doldurucular ve ara fazdan oluşurlar ve polimerizasyon şekillerine göre 3'e ayrılırlar:

1- Kimyasal olarak polimerize olanlar (chemical-cure)

2- Işık ile polimerize olanlar (light-cure)

3- Hem kimyasal hem de ışıkla polimerize olanlar (dual-cure)

Yüksek fiziksel ve mekanik dayanıklılıkları vardır. Çözünürlükleri düşüktür ve seramik restorasyonların da dirençlerini arttııılar. ${ }^{51,53}$

Buna karşın, hassas ve titiz bir çalışma gerektirmeleri, sertleştikten sonra zor temizlenmeleri ve kalın film tabakası oluşturmaları dezavantajları arasında sayılabilir. ${ }^{54,55}$

\section{Kor Materyalleri}

Korlar, kayıp olan koronal diş dokularının post yapısı üzerinde kesilmiş diş preparasyonu şeklindeki restorasyon bölümleridir. ${ }^{42}$ İdeal bir kor materyali, diş dokusu ve seçilen post sistemi ile uyumlu olmalıdır.

Döküm post-kor restorasyonlarda post ve kor bütün olarak dökülüp, birlikte değerlendirilirken, prefabrik postlarda ise amalgam, cam iyonomer siman, seramik materyaller ve kompozit rezinler kor materyali olarak kullanılabilir. ${ }^{56}$ Kor materyalleri, mekanik direnç, boyutsal stabilite, elastiklik modülü gibi uygun mekanik özellikleri taşımalıdır ve uygulanması kolay olmalıdır. ${ }^{42}$ Post-kor sisteminde görülen stres dağılımı, seçilen kor materyalinden etkilenir. ${ }^{57}$

\section{Amalgam Korlar}

Amalgam, kor materyali olarak uzun yıllardır kullanılmaktadır. Uygulanması kolay, iyi mekanik özellikte, postlar, pinler veya diğer retantif unsurlarla uyumlu olan bir kor yapı malzemesidir. ${ }^{58}$ Amalgam kor, kalan diş dokusunun yeterli olduğu olgularda daha başarılıdır. $^{59}$ Amalgamın diş dokularıyla uyumsuz termal genleşme katsayısı, düşük korozyon direnci, uzun sertleşme zamanı ve olumsuz estetik özellikleri dezavantajları arasındadır. ${ }^{44}$ Bunların yanı sıra, amalgam korlar rezin esaslı simanlarla yapsştırılan estetik kuronlara yeterince bağlanamamaktadır.

\section{Cam Iyonomer Korlar}

Cam iyonomer simanlar, diş yapısına benzer düşük termal genleşme katsayısına sahip olmaları, ${ }^{60}$ mine ve dentine kimyasal olarak bağlanmaları ${ }^{61}$ ve fluorür iyonu salmaları sebebiyle kor materyali olarak tercih edilmektedirler. Bu olumlu özelliklerine rağmen; gümüş içeren veya içermeyen cam iyonomer simanların kor materyali olarak kullanımı, çekme dayanımları ve kırılma dirençlerinin yetersiz olması sebebiyle uygun değildir. ${ }^{62}$ Kompozit rezinlerle cam iyonomerlerin üstün özelliklerini kombinleyen rezin modifiye cam iyonomer simanlar ve poliasit modifiye kompozit rezinler, nemden etkilenme gibi olumsuz özellikleri ortadan kaldırmışlardır. ${ }^{48}$

Rezin modifiye cam iyonomerlerin hem ışıkla polimerizasyon hem de asit-baz reaksiyonu ile sertleştikleri, sertleşme işlemi tamamlandıktan sonra ise geleneksel cam iyonomer simanlardan daha üstün bir materyale dönüştükleri belirtilmektedir. ${ }^{63}$ Cam iyonomerlerin başta makaslama direnci olmak üzere, her türlü direnç altındaki başarısızlığının yanında; su emerek yapılarının zayıflaması kırılmalarına neden olmaktadır. Rezin modifiye cam iyonomer simanlar rezin içerdiklerinden dolayı erken nem kontaminasyonuna direnç kazanmışlardır. Poliasit modifiye kompozit rezinler ise dentin bağlayıcı sistemlerinin yardımıyla dentin tübüllerinde rezin uzantıları meydana getirerek çok iyi bağlanma özellikleri göstermişlerdir. ${ }^{63,64}$

\section{Rezin Korlar}

Kor materyali olarak kompozit rezinler restoratif diş hekimliğinde oldukça sık kullanılmaktadır. Kullanım kolaylıkları, estetikleri ve polimerizasyonlarının kontrol altında olması klinikte tercih edilme sebepleri arasındadır. ${ }^{65}$ Kompozit rezinlerin dentin bağlayıcılarla birlikte kullanımı, diş yapısına yüksek bağlanma dayanımı sağlar ve bu da retansiyon artışına neden olur. Mekanik özellikleri ve kimyasal bağlantı avantajları nedeniyle; aşırı madde kaybına uğramış dişlerde başarıyla kullanılabilmektedirler. Doldurucularının cinsi ve miktarına bağlı olarak sertlikleri bazı ürünlerde dentinin sertlik oranına kadar yükseltilmiştir ve bu da sonradan yapılacak olan preparasyonu kolaylaştırmaktadır. Elastiklik modülleri dentine eşit veya daha yüksektir ve bu özellikler materyale direnç artışı sağlamaktadır. Ayrıca anterior dişlerde, tam seramik restorasyonlarla birlikte kullanıldığında estetik avantajları da mevcuttur. ${ }^{66}$ Günümüzde kullanılan modern kompozitlerin önemli problemlerinden birisi de kenar uyumudur. Bağlayıcı sistemlerdeki gelişmeler ve ışıkla sertleşen kompozitlerin tabakalı yerleştirilmesi, kenar bütünlüğünün korunmasında önemli ölçüde katkı sağlamıştır. Ancak bu özellikler polimerizasyon büzülmesini tamamen ortadan kaldıramamıştır. ${ }^{67}$ Polimerizasyon büzülmesi 
restorasyonun kenar uyumunu olumsuz yönde etkiler ve kavite duvarları ile rezin arasında bir boşluk oluşur. $\mathrm{Bu}$ boşluktan sızan sıvılar, bakteri ve iyonlar marjinal renklenme, kırılma ve ikincil çürük gibi olumsuzluklara yol açabilirler. ${ }^{62}$

\section{Seramik Korlar}

Son dönemde yüksek kırıma dayanımına sahip seramiklerin anterior dişlerde kor malzemesi olarak kullanımı yaygınlaşmıştır. Bu materyaller estetik avantajın yanı sıra, kullanılan seramiğin cinsine bağlı olarak yapılacak yüzey işlemlerinin ardından diş yapısına kimyasal olarak da bağlanabilirler. Laboratuarda önceden hazırlanmış bir postun etrafına presleme ile bir kor yapı oluşturulabilir veya cam infiltre alümina seramikten tek parça post-kor dökümü yapılabilir. Bir diğer seçenek ise post ve kor yapının ayrı ayrı hazırlanması ve yerleştirme sırasında birbirlerine yapıştırılmasıdır. ${ }^{68}$

\section{Post Yapıștırma ve Kor Yapımında Birlikte Kullanulan Rezin Simanlar ve Monoblok Materyal Konsepti}

Kök kanal tedavisi yapılmış dişlerin restorasyonlarında sızdırmazlığı sağlamak ve dayanıklılı̆ı arttırmak için homojen ve monoblok bir yapı oluşturmak esastır. ${ }^{69}$ Monoblok restorasyon konsepti, post ve korun sağlam olarak birbirine bağlı, devamlılık götseren materyallerle oluşturulması anlamına gelmektedir. $\mathrm{Bu}$ konsept restorasyonu tek parça haline getirip dişi güçlendirmeyi hedefler. ${ }^{70}$ Kullanılan bütün materyallerin birbirleriyle ve diş dokularıyla benzer fiziksel özellikler taşıyıp, kusursuz bir bağlanma oluşturmaları ile monoblok konsepte uygun restorasyonlar yapılabilir. Dentinin elastiklik modülüne yakın değerlere sahip materyallerin kullanımı restorasyonun başarısını arttırmaktadır. Tay ve Pashley ${ }^{69}$ çalışmalarında monoblok sistemleri, "primer", "sekonder" ve "tersiyer" olmak üzere 3' e ayırmışlardır. Buna göre, "primer" monoblok sistemler; kök dentini ve kök kanal dolgu maddesi arasındaki birleşimi içermektedir. "Sekonder" mono- blok sistemler, kök dentini, rezin siman ve cam fiber post birleşimini içermektedir. "Tersiyer" monoblok sistemler ise, kök dentini, rezin siman, cam fiber üze- rinde silan ve cam fiber post birleşimini içermektedir. Monoblok sistemlerde primerden tersiyere gidildikçe restorasyon üzerindeki materyal ve bu materyallerin birleşme yüzey sayısı artmakta bu da monoblok sistem oluşturmayı zorlaştırmaktadır.
$\mathrm{Bu}$ sebeple günümüzde, hem kor yapımında, hem de fiber post simantasyonunda kullanılabilen materyaller üretilmiştir. Piyasaya sürülen bu ürünlerle, yapılacak olan post-endodontik restorasyonda kullanılacak olan materyal sayısı azaltılarak, monoblok sistemin oluşmasına katkıda bulunmak amaçlanmıştır. Oluşturulan monoblok sistem yardımıyla restorasyonda farklı amaçlar için kullanılan tek bir materyalin, diğer materyaller ve dentinle maksimum derecede uyum sağlayarak güçlü bir nihai restorasyon ortaya çıkarması beklenmektedir. ${ }^{70}$ Restorasyonda kullanılan materyal çeşidinin azalması, restorasyon için kritik bölgeleri oluşturan arayüz sayısını da azaltmaktadır. ${ }^{71}$ Yapılan bir çalışmaya göre, monoblok post-kor materyallerin kullanıldığı örnekler, post simantasyonu için bir yapıştırma simanı ve kuronal restorasyon için bir rezin kor materyali kullanılan örnekler kadar dayanıklı ve sızdırmaz bulunmuştur. ${ }^{72}$ Ayrıca monoblok post-kor setlerinde materyal çeşidinin azaltılıp, uygulama aşamalarının kolaylaştırılmasının, geleneksel yöntemlere göre daha pratik ve zaman kazandırıcı olduğu görülmüştür. ${ }^{72}$

Günümüzde piyasada çeşitli monoblok post-kor restorasyon materyalleri bulunmaktadır. Gradia Core (GC, Tokyo, Japonya), Clearfil DC Core Plus (Kuraray, Osaka, Japonya), Core X Flow (Dentsply, DeTrey, Almanya), Corecem (RTD, St Egrève, Fransa), Rebilda DC (Voco, Cuxhaven, Almanya) ve Luxacore Z (DMG, Hamburg, Almanya) bu grup materyallere ait bazı ürünlerdir.

\section{SONUÇ}

Aşırı kuron harabiyetli dişlerin endodontik tedavi sonrası biyomekanik dayanıklılığını arttırarak uzun süre ağızda kalmasını sağlamak adına günümüze dek bir çok materyal üretilmiş ve geliştirilmiştir. Bu materyallerin seçiminde, dentine fiziksel olarak yakın özellikler taşıma, fonksiyonel kuvvetlere yeterli direnç gösterme, fonksiyon sırasında kalan diş dokularına zarar vermeme ve hasta başında geçen süreyi kısaltma gibi kriterleri göz önünde bulundurmak gerekmektedir. Ancak yine de materyallerin güvenilirliği hakkındaki en kapsamlı veriler uzun dönemli klinik çalışmaların takibi sonucu ortaya çıkabilir. 


\section{KAYNAKLAR}

1. Caputo AA, Standlee JP. Biomechanics in clinical dentistry. Quintessence Publishing Co; Chicago: 1987. p.185-203.

2. Sorensen JA, Martinoff JT. Intracoronal reinforcement and coronal coverage: a study of endodontically treated teeth. J Prosthet Dent 1984; 51: 780-4.

3. Sedgley CM, Messer HH. Are endodontically treated teeth more brittle? J Endod 1992; 18: 3325.

4. Huang TJ, Schilder $H$, Nathanson D. Effect of moisture content and endodontic treatment on some mechanical properties of human dentin. J Endod 1992; 18: 209-15.

5. Reeh ES, Messer $\mathrm{HH}$ and Douglas WH. Reduction in tooth stiffness as result of endodontic and restorative procedures. J Endod 1989; 15: 512-6.

6. Trope M, Ray HL Jr. Resistance to fracture of endodontically treated roots. Oral Surg Oral Med Oral Pathol 1992; 73: 99-102.

7. Fernandes AS, Dessai GS. Factors affecting the fracture resistance of post-core reconstructed teeth: A review. Int J Prosthodont 2001; 14: 35563.

8. Leary JM, Aquilino SA, Svare CW. An evaluation of post length within the elastic limits of dentin. J Prosthet Dent 1987; 57: 277-81.

9. Çalışkan MK. Endodontide tanı ve tedaviler. Nobel Tıp Kitabevleri; İzmir: 2006. p.463-506.

10. Chapman KW, Worley JL, Von Fraunhofer JA. Retention of prefabricated posts by cements and resins. J Prosthet Dent 1985; 54: 649-52.

11. Tjan AH, Whang SB. Retentive properties of some simplified dowel-core systems to cast gold dowel and core. J Prosthet Dent 1983; 50: 203-6.

12. Chan FV, Harcourt JK, Brockhurst PJ. The effect of post adaptation in the root canal on retention of posts cemented with various cements. Aust Dent J 1993; 38: 39- 45.

13. Çakmakçıŏlu Ö, Aktepe E. Endodontik tedavi görmüş dişlerin post sistemleriyle restorasyonu. Atatürk Üniv Dişhek Fak Derg 2003; 13: 72-80.

14. Akkayan B, Caniklioğlu MB. Farklı post tiplerinin kök kırıklarına etkileri ve post seçim kriterleri. Hacettepe Üniv Dişhek Fak Derg 1997; 21: 75-84.
15. Freedman GA. Esthetic post and core treatment. Dent Clin North Am 2001;45:103-16.

16. Qualtrough AJ, Mannocci F. Tooth colored post systems: A review. Oper Dent 2003; 28: 86-91.

17. Özdemir E. Dinamik Yüklemenin ve Farklı Adeziv Sistemlerin Fiber Postla Restore Edilmiş Dişlerde Mikrosızıntı Üzerine Olan Etkisi. Başkent Üniversitesi, Sağlık Bilimleri Enstitüsü, Ankara, 2010, Doktora Tezi.

18. Schwartz RS, Robbins JW. Post placement and restoration of endodontically treated teeth: a literature review. J Endod 2004; 30: 290-301.

19. Meyenberg KH, Luthy $\mathrm{H}$, Scharer P. Zirconia posts: A new all ceramic concept for nonvital abutment teeth. J Est Dent 1995; 7: 73-80.

20. Torbjorner A, Karlsson S, Syverud M, HenssenPettersen A. Carbon fiber reinforced root canal posts, mechanical and cytotoxic properties. Eur J Oral Sci 1996; 104: 605-11.

21. Duret B, Reynaud M, Duret F. New concept of coronoradicular reconstruction: the Composipost. Chir Dent Fr 1990; 60: 131-41.

22. King PA, Setchell DJ. An in vitro evaluation of prototype CFRC prefabricated post developed for the restoration of pulpless teeth. J Oral Rehabil 1990; 17: 599-609.

23. Asmussen E, Peutzfeldt A, Heitmann T. Stiffness, elastic limit, and strength of newer types of endodontic posts. J Dent 1999; 27: 275-8.

24. Bateman G, Ricketts DN, Saunders WP. Fibrebased post systems: a review. Br Dent J 2003; 195: 43-8.

25. Lassila LVJ, Tanner J, LeBell AM, Narva K, Vallittu PK. Flexural properties of fiber reinforced root canal posts. Dent Mater 2004; 20: 29-36.

26. Kanie T, Arikawa H, Fujii K, Bans S. Impact strength of acrylic denture base resin reinforced with woven glass fiber. Dent Mater 2003; 2: 30-8.

27. Vallittu PK, Lassila VP, Lappalainen R. Transverse strength and fatigue of denture acrylic-glass fiber composite. Dent Mater 1994; 10: 116-21.

28. Andreopoulus AG, Papaspyrides CD, Tsilibonvidis S. Surface treated polyethylene fibers as reinforcement for acrylic resins. Biomaterials 1991; 12: 83-7. 
29. Torbjorner A, Fransson B. A literature review on the prosthetic treatment of structurally compromised teeth. Int J Prosthodont 2004; 17: 369-75.

30. Newman MP, Yaman P, Dennison, J, Rafter M, Billy E. Fracture resistance of endodontically treated teeth with composite post. J Prosthet Dent 2003; 89: 360-7.

31. Vallittu PK, Lassila P. Reinforcement of acrylic resin denture base material with metal or fibre strengtheners. J Oral Rehabil 1992; 19: 225-30.

32. Yazdanie N, Mahood M. Carbon fiber acrylic resin composite: An investigation of transverse strength. J Prosthet Dent 1985; 54: 543-7.

33. Purton DG, Payne JA. Comparison of carbon fiber and stainless steel root canal posts. Quintessence Int 1996; 27: 93-7.

34. Goldberg AJ, Burstone $\mathrm{CJ}$. The use of continious fiber reinforcement in dentistry. Dent Mater 1992; 8: 197-202.

35. Mannocci $F$, Ferrari $M$, Watson TF. Intermittent loading of teeth restored using quartz fiber, carbon-quartz fiber and zirconium dioxide ceramic root canal posts. J Adhes Dent 1999; 1: 153-8.

36. Murphy J. Reinforced Plastics Handbook. Elsevier; Oxford: 1998. p.63-106.

37. Braden M, Davy KW, Parker S, Ladizinsky NH, Ward IM. Denture base polymethyl methacrylate reinforced with ultra-thin modulus polyethylene fibers. Br Dent J 1988; 164: 109-13.

38. Hornbrook DS, Hastings $\mathrm{JH}$. Use of bondable reinforcement fiber for post and core build-up in an endontically treated tooth: maximizing strength and aesthetics. Pract Periodontics Aesthet Dent 1995; 7: 33-42.

39. Sidoli GE, King PA, Setchell DJ. An in vitro evaluation of a carbon fiber-based post and core system. J Prosthet Dent 1997; 78: 5-9.

40. Ladizesky $H$, Chow W. Reinforcement of complete denture bases with continious high performance polyetheylene fibres. J Prosthet Dent 1992; 68: 934-41.

41. Morgano SM, Brackett SE. Foundation restorations in fixed prosthodontics: current knowledge and future needs. J Prosthet Dent 1999; 82: 643-57.

42. Alaçam T, Nalbant L, Alaçam A. İleri Restorasyon Teknikleri. Polat yayınları; Ankara: 1998.
43. Smith RT, Shivapuja KP. The evaluation of dual cement resins in orthodontic bonding. Am J Orthod Dentofac Orthop 1993; 103: 448-51.

44. O'Brien WJ. Dental materials and their selection. 3rd ed. Quintessence Publishing; Chicago: 2002. p.218-26.

45. Wassell RW, Barker D, Steele JG. Crowns and other extra-coronal restorations: Try-in and cementation of crowns. Br Dent J 2002; 193: 1728.

46. Wilson $A D$, Kent $B E$. A new translusent cement for dentistry: The glass ionomer cement. $\mathrm{Br}$ Dent J 1972; 132:133-5.

47. Christensen GJ. When to use fillers, build-ups or posts and cores, J Am Dent Assoc 1996; 127: 1397-8.

48. Dayangaç B. Kompozit rezin restorasyonlar. Güneş Kitabevi; Ankara: 2000. p.158-163.

49. Köroğlu A, Ekren O, Kurtoğlu C. Geleneksel ve adeziv dental simanlar hakkında bir derleme çalışması. Atatürk Üniv Dişhek Fak Derg 2012; 22: 205-16.

50. Stockton LW. Factors affecting retention of post systems: a literature review. J Prosthet Dent 1999; 81: 380-5.

51. Diaz-Arnold AM, Vargas MA, Haselton DR. Current status of luting agents for fixed prosthodontics. J Prosthet Dent 1999; 81: 135-41.

52. Nakabayashi N, Kojima K, Masuhara E. The promotion of adhesion by the infiltration of monomers into tooth substrates. J Biomed Mater Res 1982; 16: 265-73.

53. Crispin BJ, Hewlett ER, Jo YH, Hobo S, Hornbrook D. Ceramic veneers, "Contemporary Esthetic Dentistry: Practice Fundamentals". Quintessence Publishing Co, Tokyo 1994; 241-91.

54. Oguyinka A. The bond of two adhesive resins to alumina blasted and heat-treated gold alloy surfaces. J Oral Rehabil 2000; 27: 394-402.

55. Roulette JF, Degrange M. Adhesion: The silent revolution in dentistry. Quintessence Publishing Co Inc; London: 2000. p. 13-29.

56. Pilo R, Cardash HS, Levin E and Assif D. Effect of core stiffness on the in vitro fracture of crowned endodontically terated teeth. J Prosthet Dent 2002; 88: 302-6. 
57. McLean A. Predictably restoring endodontically treated teeth. J Can Dent Assoc 1998; 64: 782-7.

58. Kane JJ, Burgess JO, Summitt JB. Fracture resistance of amalgam coronalradicular restorations. J Prosthet Dent 1990; 63: 607-13.

59. Yanıkoğlu N, Bayındır F. Post-kor yapımında kullanılan restoratif materyaller ve özellikleri. Atatürk Üniv Dişhek Fak Derg 2003-2004; 13-14: 39-47.

60. Shillingburg HT, Kessler JC. Restoration of the endodontically treated teeth. Quintessence Publishing Co Inc; Chicago: 1982. p.22-24.

61. Lacefield WR, Reindl MC, Retief DH. Tensile bond strength of a glass-ionomer cement. J Prosthet Dent 1985; 53: 194-8.

62. Gateau P, Sabek M, Dailey B. Fatigue Tesring and Microscopic Evaluation of Post and Core Restorations Under Artifical Crowns. J Prosthet Dent 1999; 82: 341-7.

63. Zaimoğlu A, Can G, Ersoy F, Aksu L. Dişhekimliğinde maddeler bilgisi. Ankara Üniversitesi Basımevi; Ankara: 1993. p. 334-41.

64. Yıldız M, Bayındır Y. Rezin modifiye cam-ionomer simanlar ve poliasit modifiye kompozit rezinler (Kompomer). Atatürk Üniv Diş Hek Fak Derg 2000; 10: 55-9.

65. Millstein PL, Nathanson D. Effect of temporary cementation on permanent cement retention to composite resin cores. J Prothet Dent 1992; 67: 856-9.

66. Kostka E, Roulet JF. Textbook of endodontology (Ed. by Bergenholtz G, Bindsley PH, Reit C). 1st ed. Blackwell Publishing Co; Singapore: 2003. p. 177-91.

67. Versluis A, Douglas WH, Cross M, Sakaguchi RL. Does an incremental filling technique reduce polymerization shrinkage stresses? J Dent Res 1996; 75: 871-8.

68. Koutayas SO, Kern M. All Ceramic Post and cores: the state of art. Quintessence Int 1999; 30: 38392.

69. Tay FR, Pashley DH. Monoblocks in Root Canals- A Hypothetical or Tangible Goal. J Endod 2007; 33: 391-8.

70. Hegde VS, Khatavkar RA. The weak link in endodontics: Gutta percha- a need for change. World J Dent 2010; 1: 217-24.
71. Radovic I, Mazitelli C, Chieffi N, Ferrari M. Evaluation of adhesion of fiber posts cemented using different adhesive approaches. Eur J Oral Sci 2008; 116: 557-63.

72. Yıldırım G. Fiber Post Simantasyonu ve Üst Yapıda Kullanılan Rezin Esaslı Materyallerin Mekanik Özelliklerinin ve Mikrosızıntılarının Karşılaştıııması. Ege Üniversitesi, Sağlık Bilimleri Enstitüsü, İzmir, 2014, Doktora Tezi.

\section{Yazışma Adresi}

Dr. Gamze KARAÇOLAK

Ege Üniversitesi

Diş Hekimliği Fakültesi

Restoratif Diş Tedavisi A.D.

Bornova 35100 İzmir/Türkiye

Tel: 0232-3112863

e-posta: gyildirim84@hotmail.com 